\title{
The Logic of Testing Structural Change in Meat Demand: A Methodological Analysis and Appraisal
}

\author{
George C. Davis \\ American Journal of Agricultural Economics, Vol. 79, No. 4. (Nov., 1997), pp. 1186-1192.
}

Stable URL:

http://links.jstor.org/sici?sici=0002-9092\%28199711\%2979\%3A4\%3C1186\%3ATLOTSC\%3E2.0.CO\%3B2-B

American Journal of Agricultural Economics is currently published by American Agricultural Economics Association.

Your use of the JSTOR archive indicates your acceptance of JSTOR's Terms and Conditions of Use, available at http://www.jstor.org/about/terms.html. JSTOR's Terms and Conditions of Use provides, in part, that unless you have obtained prior permission, you may not download an entire issue of a journal or multiple copies of articles, and you may use content in the JSTOR archive only for your personal, non-commercial use.

Please contact the publisher regarding any further use of this work. Publisher contact information may be obtained at http://www.jstor.org/journals/aaea.html.

Each copy of any part of a JSTOR transmission must contain the same copyright notice that appears on the screen or printed page of such transmission.

The JSTOR Archive is a trusted digital repository providing for long-term preservation and access to leading academic journals and scholarly literature from around the world. The Archive is supported by libraries, scholarly societies, publishers, and foundations. It is an initiative of JSTOR, a not-for-profit organization with a mission to help the scholarly community take advantage of advances in technology. For more information regarding JSTOR, please contact support@jstor.org. 


\title{
The Logic of Testing Structural Change in Meat Demand: A Methodological Analysis and Appraisal
}

\author{
George C. Davis
}

\begin{abstract}
In the past two decades, the profession has expended valuable resources testing structural change in meat demand with mixed results. Overlooked to date is a fundamental methodological problem that transcends all methods of testing for structural change. In this study, a methodological framework is used to show that there is no valid test of structural change. Because of this result, additional criteria from the methodology literature are used to evaluate the literature on structural change in meat demand and to provide suggestions for fertile areas of future research.
\end{abstract}

Key words: demand, logic, methodology, Popper-Duhem dilemma, structural change.

\begin{abstract}
But whatever be the "explanation" we prefer, it is not to be forgotten that they are all our own artificial inventions in a search for an understanding of real life; they are not hidden truths to be "discovered."
\end{abstract}

-T. Haavelmo (p. 3)

A "true model" is an oxymoron if there ever was one.

-D. Poirier (p. 598)

Structural change (i.e., a change in preferences) is commonly hypothesized to be the cause of the change in meat consumption over the past decade, and many researchers have attempted to test this hypothesis. However, in the 1986 book edited by Buse titled The Economics of Meat Demand, several authors reached the following conclusions: (a) varying parameters tests for structural change are uninformative, (b) hypotheses other than structural change should be pursued to explain the change in meat consumption, and (c) testing for structural

\footnotetext{
The author is an assistant professor in the Department of Agricultural Economics, Texas A\&M University.

Special thanks is extended to John Nolt in the Department of Philosophy at the University of Tennessee for enlightening discussions related to this paper and his instruction in formal logic. Appreciation is also expressed to Greg Pompelli, Paul Jakus, Jean Gauger, and the students in my methodology class at the University of Tennessee for assistance with an earlier draft of this paper. I am especially grateful to David Bessler at Texas A\&M University for his insights and encouragement in this research.
}

change is intractable (see pp. 14-16, 54, 95, $103,113,128$, and 202). Despite these admonitions, testing structural change is still an active area of research. A look at the agricultural economics literature between 1986 and 1996 reveals that at least twenty articles have been published that focus on structural change in meat demand in that time period. ${ }^{1}$ What does this research record suggest for the conclusions reached in The Economics of Meat Demand? At a minimum, the record indicates that testing for structural change is not viewed by many as an intractable problem. This is not surprising, given that the claim has never been proven.

The objective of this paper is to answer two questions: Can structural change ever be tested? and, If structural change cannot be tested, how should the research proceed? Although several studies have contributed to our understanding of the problem of testing for structural change (e.g., Alston and Chalfant 1991a, b; Chalfant and Alston; McGuirk et al.), these have considered only a small part of a much larger problem. As a result, they have provided only limited guidance as to how research should proceed.

In this paper, a methodological review of models and the logic of hypothesis testing is

\footnotetext{
${ }^{1}$ A list of these articles can be found in Davis
} 
given. Within this framework, it is shown that structural change can never be tested, so additional hypothesis evaluation criteria from the methodology literature are used to evaluate the alternative approaches pursued in explaining the change in meat demand. This evaluation provides examples of research that is and is not considered progressive on the basis of these additional criteria. The paper ends with conclusions.

\section{A Methodological Review of Models and the Logic of Hypothesis Testing}

To determine whether structural change can ever be tested, an analytical framework is required that is general enough to apply to any method of testing structural change. Such a framework is provided by (formal) logic. ${ }^{2}$ Conducting a logical analysis first requires a general characterization of the steps involved in empirically testing a hypothesis. These steps are characterized by the relationships between theoretical models, partial theoretical models, empirical models, and estimated models, as alluded to in Darnell and Evans; Kim, DeMarchi, and Morgan; Spanos; and Stewart. Once these relationships are established, results from introductory logic can be used to determine whether there exists a valid test of structural change.

\section{Theoretical, Partial Theoretical, Empirical, and Estimated Models}

An economist who wants to test a hypothesis must make five major assumptions before conducting any test. Specific hypotheses or assumptions are denoted as $A_{i}$, and $i$ indexes the assumption being made.

The first set of assumptions are theoretical conceptual assumptions, which formalize the conceptual theory and from which the implications of the theory are derived. The two key theoretical conceptual assumptions for structural change are usually that there exists a representative consumer that maximizes a static utility function subject to a budget constraint

\footnotetext{
${ }^{2}$ Technically speaking, the analytical framework presented in this section is a simple metalanguage. As Tarski has proven, to determine whether the correspondence between a statement (e.g., a hypothesis) and a fact (e.g., change in consumption) is true, a metalanguage must be implemented. Because no metalanguage has been established to analyze the question of testing structural change, Tarski's analysis explains why no closure has come on this issue.
}

$\left(A_{1}\right)$ and that the "true" utility function has not changed $\left(A_{2}\right){ }^{3}$ Assumptions $A_{1}$ and $A_{2}$ generate the theoretical model, or "true" demand system.

The second major set of assumptions are theoretical bridging assumptions, which constitute the first step in making the theory empirically accessible. ${ }^{4}$ Because $A_{1}$ and $A_{2}$ generate a complete demand system for all goods and services, the prohibitively large dimensions of the theoretical demand system must be reduced through some dimension reduction assumption(s) $\left(A_{3}\right)$ (e.g., an aggregation assumption such as weak separability). This is the key theoretical bridging assumption. The assumptions in $A_{3}$ generate a partial theoretical model, which is a special case of the theoretical model.

The third major set of assumptions are empirical bridging assumptions, of which there are three key ones. First, if the analysis is to be parametric, a functional form assumption must be made $\left(A_{4}\right)$ (e.g., a translog). Second, the observational units must be chosen $\left(A_{5}\right)$ (e.g., months, years, households, or countries). Third, the measurement variables must be chosen $\left(A_{6}\right)$ (e.g., average price or a superlative price index). Assumptions $A_{4}, A_{5}$, and $A_{6}$ generate an empirical model, which is only one of many possible representations of the partial theoretical model. In econometric parlance, the empirical model is the population model.

The fourth major set of assumptions are the estimation technique assumptions $\left(A_{7}\right)$, which generate an estimated model of the empirical model. From the estimated model, a metric of a particular value, say $M$, is generated that can be used to evaluate the estimated model. In a parametric setting, this metric may be a statistical test, such as an $F$-test; in a nonparametric setting, this metric may be something like the number of violations of the weak axiom of revealed preferences. In either case, the metric $M$ is a function of the chosen data and represents a consequent of the assumptions that have been put forth. Finally and implicitly, ceteris paribus assumptions $\left(A_{8}\right)$ are made to restrict the range of the phenomenon under consideration.

\footnotetext{
${ }^{3}$ The assumption of the existence of a representative consumer utility function makes the issue of aggregation over individuals irrelevant. Although plenty of evidence indicates that aggregation over individuals is problematic, the assumption is made here because it is often used in the literature, and relaxing the assumption would only strengthen the results of this paper.

${ }^{4}$ The term bridging assumption is attributable to Hemple.
} 


\section{The Logic of Hypothesis Testing}

Methodology, by definition, is the logic of methods; therefore, all science can be considered applied logic (Cohen and Nagel, p. 191). The fundamental problem that is occurring in testing the structural change hypothesis is an error in logic. With the general empirical structure given in the previous section, the argument for testing structural change is either one of the two following logical forms:

1. If $\left(A_{1}\right.$ and $A_{2}$ and $A_{3}$ and $\ldots$ and $\left.A_{8}\right)$ are all true (in some sense), then $M$ is true (in the same sense). $M$ is true; therefore, $A_{2}$ is true.

2. If $\left(A_{1}\right.$ and $A_{2}$ and $A_{3}$ and $\ldots$ and $\left.A_{8}\right)$ are all true, then $M$ is true. $M$ is not true; therefore, $A_{2}$ is not true.

Each of these arguments is an example of what in logic is called a hypothetical syllogism. The " $\left(A_{1}\right.$ and $A_{2}$ and $A_{3}$ and ... and $\left.A_{8}\right)$ " is called the antecedent, or theoretical system (Duhem), and the " $M$ " is called the consequent. It is a trivial exercise in formal logic to prove that both these arguments are invalid. These proofs can be found in Davis. ${ }^{5}$

Popper's (1968) falsification philosophy of science is based on the fallacy of the first argument, which is often referred to as the fallacy of verification because the consequent of the argument $(M)$ is verified. Unfortunately, falsification is valid only for falsifying the entire theoretical system; it is not valid for falsifying an individual hypothesis within the theoretical system. Duhem recognized that this limits the role of falsification in science and also makes the second argument invalid. For this reason, the second fallacy is usually referred to as $D u$ hem's thesis or the fallacy of falsification, given that the consequent of the argument $(M)$ is falsified.

Scientists are then caught in what may be termed the Popper-Duhem dilemma: Whereas Popper's falsification criteria rules out verification, Duhem's thesis rules out falsifying a single hypothesis within a theoretical system. The only valid form of hypothesis testing is to falsify all hypotheses making up the theoretical system. A single hypothesis that must be combined with other hypotheses to make it testable cannot be falsified or verified.

Agricultural economists have recognized

\footnotetext{
'As long as $A_{2}$ (constant preferences) and $M$ (null hypothesis of insignificant metric) are defined to be consistent with each other, the results of the text hold. Therefore, redefining $A_{2}$ and $M$ to be the opposite, that is, $A_{2}$ (nonconstant preferences) and $M$ (null hypothesis of significant metric), will not change the results presented in the text.
}

specific applications of the Popper-Duhem dilemma but have not recognized the more general principle and its implications for testing structural change. ${ }^{6}$ For example, although the articles by Alston and Chalfant, Chalfant and Alston, and McGuirk et al. correctly point out the limitations of parametric methods in drawing inferences on structural change, by focusing on these problems others are lured into believing that improved techniques, both parametric and nonparametric, will lead to a valid test of structural change. Nonparametric tests do not provide an "ideal test" of structural change, and "better data or better methods" will not provide "valid inferences" regarding structural change, as claimed by Alston and Chalfant (1991, p. 47), because the Popper-Duhem dilemma still applies.

Similarly, extensive diagnostic testing in parametric models as advocated by McGuirk et al. is indeed important; however, in the end, the Popper-Duhem dilemma still applies. In parametric analysis, the problem is that even if a divine econometrician told us the true functional form and parameter values of our empirical model - the ultimate diagnostic testthese parameter estimates are always biased estimates of those in the theoretical model because by definition the empirical model omits some variables that are in the theoretical model. This admonition just echos the forgotten distinction that was made between statistical demand curves and theoretical demand curves by the forefathers of econometrics (see Stigler) and that Caldwell so succinctly summarizes: "Tests of models are not tests of theories" (p. 493). Therefore, the first question has been answered: Structural change as defined as a change in preferences cannot be tested without violating the laws of logic.

\section{Additional Methodological Criteria}

According to the Popper-Duhem dilemma, hypothesis testing is not a sufficient condition for falsifying or verifying the hypothesis of structural change. To make scientific progress, then, it is necessary to consider criteria in addition to hypothesis testing, and Lakatos develops these criteria. These additional criteria provide

\footnotetext{
${ }^{6}$ It should be noted that the recent article by Bessler and Dearmont does discuss the closely related problem of uncontrolled experiments and the role of ceteris paribus in discovering structure. They come to a conclusion similar to that expressed here but by different means. Their analysis can also be considered a special case (although a much more general case than all the others) of the Popper-Duhem dilemma.
} 
an answer to the second question: How should the research proceed?

Lakatos recognized that Duhem's thesis allows the scientist to alter any assumption in creating a new theoretical system $T_{1}$ in an attempt to avoid falsification. For example, a researcher who believes that there has been no structural change can always claim that the finding of structural change is due to some other problematic assumption in the original theoretical system $T_{0}$ (e.g., the original functional form assumption or the separability assumption is wrong). By altering an assumption that initially may have been considered unproblematic, a new theoretical system $\left(T_{1}\right)$ is generated that may not be falsified. However, even if the new theoretical system $\left(T_{1}\right)$ is falsified, nothing can be said about structural change. The PopperDuhem dilemma still applies. Most scientific work proceeds in this fashion, where the researcher diagnoses which assumption of a theoretical system $\left(T_{0}\right)$ needs to be altered to explain a falsification or "anomaly." 7 The relevant methodological question becomes, How should alternative diagnoses be evaluated? This is the question addressed by Lakatos.

Lakatos modifies Popper's falsification criterion to address Duhem's thesis. Lakatos defines a theoretical system $\left(T_{0}\right)$ as falsified if and only if another theoretical system $\left(T_{1}\right)$ has been proposed with the following characteristics: ${ }^{8}$

(a) $T_{1}$ has excess content over $T_{0}$ by predicting novel facts that are improbable or even forbidden by $T_{0}$;

(b) $T_{1}$ explains the previous success of $T_{0}$, and all the unrefuted content of $T_{1}$ is included in the content of $T_{0}$;

(c) Some of the excess content of $T_{1}$ is corroborated.

If the alternative theoretical system $T_{1}$ satisfies

\footnotetext{
${ }^{7}$ This process is referred to as diagnostic reasoning in the methodology literature, and Janssen and Tan provide an example of diag nostic reasoning in economics.

${ }^{8}$ Lakatos's methodology is considered rather pragmatic. As Blaug (p. 32) observes, the Lakatos methodology is not as rigid and prescriptive as the naive version of Popper's falsification school, whereby a single hypothesis can be refuted by a falsifying instance. But it is more rigid and prescriptive than Kuhn's descriptive and historical account of science. For this reason, it is not surprising that Lakatos is criticized from both sides. Philosophers of science reproach him for not providing a solid demarcation principle between science and nonscience; alternatively, historians criticize Lakatos for not describing the scientific process accurately. Given that practicing economists are neither philosophers of science nor historians, they may take from Lakatos those aspects of his methodology that are recognized as advantageous and leave the rest (Cross). This approach may be referred to as a local provisional methodology (Randall). Popper (1992), Van Fraasen, and Pietroski and Rey have all proposed criteria similar to those of Lakatos.
}

(a) and $(b)$, then there is theoretical progress. If all three conditions are satisfied, there is empirical progress. De Marchi (p. 134) points out that Lakatos identifies another type of progress, which will be termed empirical basis refinement (Lakatos, p. 121, n. 4). Empirical basis refinement occurs when the technique for testing a theory is altered in a manner that provides a more accurate and appropriate test of the theory.

An important point of Lakatos's philosophy of science and what distinguishes it from Popper is that there is never absolute falsification. Rather, falsification becomes a relative or conditional contest between two competing hypotheses. As Lakatos states, "There is no falsification before the emergence of a better theory" (p. 119).

\section{A Methodological Appraisal of Alternative Diagnoses}

Lakatos's three criteria of theoretical progress, empirical progress, and empirical basis refinement can be used for evaluating the alternative diagnoses or approaches found in the literature. Rather than evaluating all articles addressing the change in the meat demand issue, the evaluation can proceed according to which types of diagnoses have been emphasized. Three main diagnoses are found in the literature for explaining the change in meat demand: (a) a change in preferences, (b) measurement or technique refinement, and $(c)$ more generalized demand structures.

The most common diagnosis of a change in preferences alters an assumption in the theoretical model $\left(A_{2}\right)$ (e.g., Choi and Sosin). The diagnosis of a change in preferences does not satisfy any of the Lakatos criteria. The main reason that this diagnosis does not satisfy any of the criteria is the claim that changing parameters imply changing preferences. The Popper-Duhem dilemma indicates that changing parameters are neither a necessary nor a sufficient condition for changing preferences. To say that varying parameters imply changing preferences is equivalent in logic to saying that constant preferences imply constant parameters. ${ }^{9}$ But constant preferences do not imply constant parameters. The constant parameters assumption originates not from the constant preferences assumption but from assuming that

\footnotetext{
${ }^{9}$ This is known in logic as transposition (see, e.g., Nolt and Rohatyn).
} 
the partial derivatives of some function can be considered constant. However, under the assumption of constant preferences, these partial derivatives generally are functions of variables and are not constant (see White). Therefore, a constant preferences assumption is also consistent with varying parameters. For this reason, the changing preferences assumption is void of any excess content over the constant preferences assumption and therefore represents no theoretical or empirical progress over the constant preferences assumption and does not refine the empirical basis.

Studies that focus on measurement or technique refinement alter an assumption in either the empirical model or the estimating model (i.e., $A_{4}$ through $A_{7}$ ). Focusing on measurement or technique refinement (e.g., measurement error, $A_{6}$, as in Atkins, Kerr, and McGivern; inverse demand systems, $A_{7}$, as in Eales and Unnevehr 1993; or nonparametrics, $A_{4}$ and $A_{7}$, as in Chalfant and Alston) satisfies only the empirical basis refinement of the Lakatos criteria. Measurement or technique refinement does not represent any theoretical or empirical progress because there is no improbable novel fact associated with the new measurement or technique that was not also associated with the old measurement or technique; rather, it represents only an inaccurate measurement. However, improving the measurement of variables and techniques for testing hypotheses is always progressive because it refines the empirical basis.

Studies that consider more general demand structures to explain the change in meat consumption alter assumptions in either the theoretical model or the partial theoretical model (i.e., $A_{1}$ through $A_{3}$ ). Considering more general demand structures satisfies all the Lakatos criteria. The dynamic specifications (e.g., Burton and Young) alter the classical static utility framework $\left(A_{1}\right)$ and are theoretically and empirically progressive because they allow lagging and leading variables, which are not allowed by static models, to influence consumption. Furthermore, static demand theory can be considered nested within the dynamic theory, so dynamic specifications can be seen as refining the empirical basis. Similarly, considering more appropriate aggregation schemes by exploring the separability assumption (e.g., Eales and Unnevehr 1988) alters the dimension reduction assumption $\left(A_{3}\right)$ and is theoretically and empirically progressive because different cross-price and expenditure relationships are generated. Furthermore, considering alternative separability conditions and therefore product aggregation schemes refines the empirical basis because a more appropriate theoretical framework is used for conducting the hypothesis test.

The most progressive of all studies are those that alter the classical static utility framework $\left(A_{1}\right)$ by considering causal factors for the socalled structural change (e.g., Gao and Shonkwiler, McGuirk et al.). Where other studies only speculate that changes in nutrition concepts or demographics may explain the observations of varying parameters, these studies proceed to incorporate some of these causal factors into the model and test the hypothesis. The incorporation of these other variables generates theoretical and empirical progress. Furthermore, because the hypothesis is considered in this more general framework, the empirical basis is refined in these studies. Because the general empirical approach is consistent with a more general theory of demand and they attempt to identify the factors causing the apparent structural change, these studies must be considered the most progressive of all the approaches.

\section{Conclusions}

The claim that there is a valid test for structural change violates the laws of logic. Structural change cannot be tested because of the PopperDuhem dilemma. The dilemma implies that competing theories can always be generated by altering a subset of the assumptions that are considered problematic. The relevant methodological question becomes, Which assumptions should be altered? Lakatos provides a set of three criteria for answering this question and argues that the assumptions that should be altered are those that yield theoretical progress, empirical progress, and empirical basis refinement. The approaches pursued in the literature were appraised on the basis of how many of the Lakatos criteria were satisfied.

A discernible pattern emerges from this evaluation that should be helpful for directing future research. Altering assumptions regarding the theoretical model $\left(A_{1}\right)$ or the partial theoretical model $\left(A_{3}\right)$ is generally a more progressive strategy than altering assumptions closer to the empirical and estimated models $\left(A_{4}\right.$ through $A_{7}$ ). The main reason for this result is that progress, both theoretical and empirical, is primarily determined by the underlying theoretical model and partial theoretical model, not the empirical model and estimating model. Once the empirical model assumptions $\left(A_{4}\right)$ are reached, most of the possible theoretical and 
empirical progress is already determined, and all that is left is empirical basis refinement of a partial theoretical model.

The predominant theoretical demand structure implemented in the literature is the classical static conditional demand theory, which consists only of contemporaneous quantities and prices within a commodity group and total expenditures on that group. The methodological evaluation presented here implies that considering a more generalized demand framework is more progressive than applying the latest parametric or nonparametric technique to this classical structure. Operationally, this may mean weakening separability assumptions by estimating food demand systems rather than only conditional meat demand systems or, alternatively, by using more generalized conditional demand theories in which the classical static conditional demand theory is nested. Conditional dynamic demand theory (Anderson and Blundell), conditional household production theory (Lancaster), or Lewbel's modifying functions are all examples of theoretically consistent approaches for generalizing the classical demand structure and incorporating other variables, such as lagged values, demographics, and product characteristics. By including these additional variables, theoretical and empirical progress is achieved relative to the classical static conditional demand theory. Furthermore, the generalized conditional demand approach will refine the empirical basis because the hypothesis is cast in a more general framework (e.g., Jorgenson and Slesnick).

With respect to meat demand, this study is not the first to suggest that pursuing more general demand structures will be more informative than refining empirical techniques (Capps and Schmitz; Haidacher; Wohlgenant). However, by providing the methodological foundations and reasons for this suggestion, this study shows why this suggestion is methodologically progressive and worthy of serious consideration.

[Received December 1995; final revision received June 1997.]

\section{References}

Alston, J.M., and J.A. Chalfant. "Can We Take the Con out of Meat Demand Studies?" W. J. Agr. Econ. 16(July 1991a):36-48.

- "Unstable Models and Incorrect Forms."
Amer. J. Agr. Econ. 73(November 1991b): 1171-81.

Anderson, G., and R. Blundell. "Testing Restriction in a Flexible Dynamic Demand System: An Application to Consumers' Expenditure in Canada." Rev. Econ. Stud. 50(1983):397-410.

Atkins, F., W. Kerr, and D. McGivern. "A Note on Structural Change in Canadian Meat Demand." Can. J. Agr. Econ. 37(1989):513-24.

Bessler, D., and D. Dearmont. "Ceteris Paribus: An Evolution within Agricultural Econometrics." Eur. J. Agr. Econ. 23(1996):262-80.

Blaug, M. The Methodology of Economics-or How Economists Explain, 2nd ed. Cambridge: Cambridge University Press, 1993.

Burton, M., and T. Young. "The Structure of Changing Tastes for Meat and Fish in Great Britain." Eur. Rev. Agr. Econ. 19(1992):16580.

Buse, R., ed. The Economics of Meat Demand. Madison: Department of Agricultural Economics, University of Wisconsin, 1989.

Caldwell, B.J. "Some Problems with Falsification in Economics." Philos. Soc. Sci. 14(December 1984):489-95.

Capps, O., Jr., and J.D. Schmitz. “A Recognition of Health and Nutrition Factors in Food Demand Analysis." W. J. Agr. Econ. 16(July 1991):21-35.

Chalfant, J.A., and J.M. Alston. "Accounting for Changes in Tastes." J. Polit. Econ. 96(1988): 391-410.

Choi, S., and K. Sosin. "Testing for Structural Change: The Demand for Meat." Amer. J. Agr. Econ. 72(1990):227-36.

Cohen, M., and E. Nagel. An Introduction to Logic and Scientific Method. New York: Harcourt, Brace and Company, 1934.

Cross, R. "The Duhem-Quine Thesis, Lakatos, and the Appraisal of Theories in Macroeconomics." Econ. J. 92(June 1982):320-40.

Darnell, A., and J. Evans. The Limits of Econometrics. Brookfield VT: Edward Elgar Publishing, 1990.

Davis, G.C. "The Formal Logic of Testing Structural Change in Meat Demand: A Methodological Analysis." Faculty Paper Series FP 97-11. Dept. of Agr. Econ., Texas A\&M University, April 1997. Available HTTP: http:// agrinet.tamu.edu/centers/ageco/publications/ fp97-11.pdf.

De Marchi, N. "Comment on Kim." Appraising Economic Theories: Studies in the Methodology of Research Programs. N. de Marchi and M. Blaug, eds., pp. 132-36. Brookfield VT: Edward Elgar Publishing, 1991.

Duhem, P. The Aim and Structure of Scientific The- 
ories. P. Wiener, trans., 1906. Princeton NJ: Princeton University Press, 1954.

Eales, J., and L. Unnevehr. "Demand for Beef and Chicken Products: Separability and Structural Change." Amer. J. Agr. Econ. 70(August 1988):521-32.

- "Simultaneity and Structural Change in U.S. Meat Demand." Amer. J. Agr. Econ. 75(May 1993):259-68.

Gao, X., and J. Shonkwiler. "Characterizing Taste Change in a Model of U.S. Meat Demand: Correcting for Spurious Regression and Measurement Errors." Rev. Agr. Econ. 15(May 1993):313-24.

Haavelmo, T. "The Probability Approach in Econometrics." Supplement to Econometrica 12(1944).

Haidacher, R. "Assessing Structural Change in the Demand for Food Commodities." S. J. Agr. Econ. 15(July 1983):31-38.

Hempel, C. "Formulation and Formalization of Scientific Theories." The Structure of Scientific Theories, 2nd ed. F. Suppe, ed., pp. 24455. Urbana IL: University of Illinois Press, 1977.

Janssen, M., and Y. Tan. "Friedman's Permanent Income Hypothesis as an Example of Diagnostic Reasoning." Econ. and Philosophy 8(April 1992):23-50.

Jorgenson, D., and D. Slesnick. "Aggregate Consumer Behavior and Household Equivalence Scales." J. Bus. and Econ. Statist. 5(April 1987):219-32.

Kim, J., N. De Marchi, and M. Morgan. “Empirical Model Particularities and Belief in the Natural Rate Hypothesis." J. Econometrics 67(May 1995):81-102.

Kuhn, T. The Structure of Scientific Revolutions, 2nd ed. Chicago: University of Chicago Press, 1970.

Lakatos, I. "Falsification and the Methodology of Scientific Research Programmes." Criticism and the Growth of Knowledge. I. Lakatos and A. Musgrave, eds., pp. 91-196. Cambridge MA: Cambridge University Press, 1993.

Lancaster, K. Modern Consumption Theory. Brookfield VT: Edward Elgar Publishers, 1991.
Lewbel, A. "A Unified Approach to Incorporating Demographic and Other Effects into Demand Systems." Rev. Econ. Stud. 52(1985):1-18.

McGuirk, A., P. Driscoll, J. Alwang, and H. Huang. "System Misspecification Testing and Structural Change in the Demand for Meats." $J$. Agr. and Res. Econ. 20(1995):1-21.

Nolt, J., and D. Rohatyn. Theory and Problems of Logic. Schaum's Outline Series in Philosophy. New York: McGraw-Hill, 1988.

Pietroski, P., and G. Rey. "When Other Things Aren't Equal: Saving Ceteris Paribus Laws from Vacuity." Brit. J. Philosophy and Sci. 46(1995):81-100.

Poirier, D. J. Intermediate Statistics and Econometrics: A Comparative Approach. Cambridge MA: MIT Press, 1995.

Popper, K. In Search of a Better World: Lectures and Essays from Thirty Years. New York: Routledge, 1992.

- The Logic of Scientific Discovery, enlarged ed. London: Hutchinson \& Co., 1968.

Randall, A. "What Practicing Agricultural Economists Really Need to Know about Methodology." Amer. J. Agr. Econ. 75(October 1993):48-59.

Spanos, A. "Toward a Unifying Methodological Framework for Econometric Modelling.' In Modelling Economic Series: Advanced Texts in Econometrics. C.W.J. Granger, ed., pp. 33568. Oxford: Clarendon Press, 1990.

Stewart, I. Reasoning and Method in Economics: An Introduction to Economic Methodology. Brookfield VT: Ashgate Publishing, 1993.

Stigler, G. J. "The Limitations of Statistical Demand Curves." J. Amer. Statist. Assoc. 34(1939):469-81.

Tarski, A. Logic, Semantics, Metamathematics. J. H. Woodger, trans. Oxford: Clarendon Press, 1956.

Van Fraasen, B. The Scientific Image. Oxford: Clarendon Press, 1980.

White, H. "Using Least Squares to Approximate Unknown Regression Functions." Int. Econ. Rev. 21(February 1980):149-70.

Wohlgenant, M. “Assessing Structural Change in the Demand for Food Commodities: Discussion." S. J. Agr. Econ. 15(July 1983):39-42. 
http://www.jstor.org

\title{
LINKED CITATIONS
}

- Page 1 of 3 -

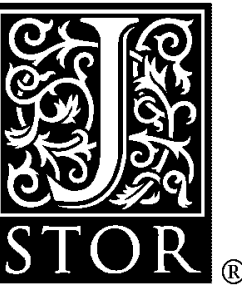

You have printed the following article:

The Logic of Testing Structural Change in Meat Demand: A Methodological Analysis and Appraisal

George C. Davis

American Journal of Agricultural Economics, Vol. 79, No. 4. (Nov., 1997), pp. 1186-1192.

Stable URL:

http://links.jstor.org/sici?sici=0002-9092\%28199711\%2979\%3A4\%3C1186\%3ATLOTSC\%3E2.0.CO\%3B2-B

This article references the following linked citations. If you are trying to access articles from an off-campus location, you may be required to first logon via your library web site to access JSTOR. Please visit your library's website or contact a librarian to learn about options for remote access to JSTOR.

\section{[Footnotes]}

\author{
${ }^{8}$ The Duhem-Quine Thesis, Lakatos and the Appraisal of Theories in Macroeconomics \\ Rod Cross \\ The Economic Journal, Vol. 92, No. 366. (Jun., 1982), pp. 320-340. \\ Stable URL: \\ http://links.jstor.org/sici?sici=0013-0133\%28198206\%2992\%3A366\%3C320\%3ATDTLAT\%3E2.0.CO\%3B2-V
}

\section{References}

\section{Unstable Models from Incorrect Forms}

Julian M. Alston; James A. Chalfant

American Journal of Agricultural Economics, Vol. 73, No. 4. (Nov., 1991), pp. 1171-1181.

Stable URL:

http://links.jstor.org/sici?sici=0002-9092\%28199111\%2973\%3A4\%3C1171\%3AUMFIF\%3E2.0.CO\%3B2-T

Testing Restrictions in a Flexible Dynamic Demand System: An Application to Consumers' Expenditure in Canada

Gordon Anderson; Richard Blundell

The Review of Economic Studies, Vol. 50, No. 3. (Jul., 1983), pp. 397-410.

Stable URL:

http://links.jstor.org/sici?sici=0034-6527\%28198307\%2950\%3A3\%3C397\%3ATRIAFD\%3E2.0.CO\%3B2-F

NOTE: The reference numbering from the original has been maintained in this citation list. 
http://www.jstor.org

\section{LINKED CITATIONS}

- Page 2 of 3 -

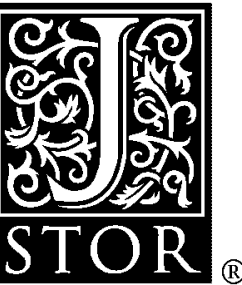

\section{Accounting for Changes in Tastes}

James A. Chalfant; Julian M. Alston

The Journal of Political Economy, Vol. 96, No. 2. (Apr., 1988), pp. 391-410.

Stable URL:

http://links.jstor.org/sici?sici=0022-3808\%28198804\%2996\%3A2\%3C391\%3AAFCIT\%3E2.0.CO\%3B2-B

\section{Testing for Structural Change: The Demand for Meat}

Seungmook Choi; Kim Sosin

American Journal of Agricultural Economics, Vol. 72, No. 1. (Feb., 1990), pp. 227-236.

Stable URL:

http://links.jstor.org/sici?sici=0002-9092\%28199002\%2972\%3A1\%3C227\%3ATFSCTD\%3E2.0.CO\%3B2-C

The Duhem-Quine Thesis, Lakatos and the Appraisal of Theories in Macroeconomics Rod Cross

The Economic Journal, Vol. 92, No. 366. (Jun., 1982), pp. 320-340.

Stable URL:

http://links.jstor.org/sici?sici=0013-0133\%28198206\%2992\%3A366\%3C320\%3ATDTLAT\%3E2.0.CO\%3B2-V

\section{Demand for Beef and Chicken Products: Separability and Structural Change}

James S. Eales; Laurian J. Unnevehr

American Journal of Agricultural Economics, Vol. 70, No. 3. (Aug., 1988), pp. 521-532.

Stable URL:

http://links.jstor.org/sici?sici=0002-9092\%28198808\%2970\%3A3\%3C521\%3ADFBACP\%3E2.0.CO\%3B2-V

\section{Simultaneity and Structural Change in U.S. Meat Demand}

James S. Eales; Laurian J. Unnevehr

American Journal of Agricultural Economics, Vol. 75, No. 2. (May, 1993), pp. 259-268.

Stable URL:

http://links.jstor.org/sici?sici=0002-9092\%28199305\%2975\%3A2\%3C259\%3ASASCIU\%3E2.0.CO\%3B2-T

Characterizing Taste Change in a Model of U.S. Meat Demand: Correcting for Spurious Regression and Measurement Errors

X. M. Gao; J. S. Shonkwiler

Review of Agricultural Economics, Vol. 15, No. 2. (May, 1993), pp. 313-324.

Stable URL:

http://links.jstor.org/sici?sici=1058-7195\%28199305\%2915\%3A2\%3C313\%3ACTCIAM\%3E2.0.CO\%3B2-V

NOTE: The reference numbering from the original has been maintained in this citation list. 
http://www.jstor.org

\section{LINKED CITATIONS \\ - Page 3 of 3 -}

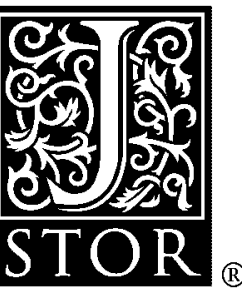

A Unified Approach to Incorporating Demographic or Other Effects into Demand Systems Arthur Lewbel

The Review of Economic Studies, Vol. 52, No. 1. (Jan., 1985), pp. 1-18.

Stable URL:

http://links.jstor.org/sici?sici=0034-6527\%28198501\%2952\%3A1\%3C1\%3AAUATID\%3E2.0.CO\%3B2-L

\section{Using Least Squares to Approximate Unknown Regression Functions}

Halbert White

International Economic Review, Vol. 21, No. 1. (Feb., 1980), pp. 149-170.

Stable URL:

http://links.jstor.org/sici?sici=0020-6598\%28198002\%2921\%3A1\%3C149\%3AULSTAU\%3E2.0.CO\%3B2-X

NOTE: The reference numbering from the original has been maintained in this citation list. 